Published in final edited form as:

Neuropsychologia. 2010 January ; 48(1): 211-219. doi:10.1016/j.neuropsychologia.2009.09.006.

\title{
Functional Neuroimaging of Self-Referential Encoding with Age
}

\author{
Angela H. Gutchess ${ }^{1,2}$, Elizabeth A. Kensinger ${ }^{2,3}$, and Daniel L. Schacter 2,4 \\ ${ }^{1}$ Department of Psychology, Brandeis University \\ ${ }^{2}$ Athinoula A. Martinos Center for Biomedical Imaging, Massachusetts General Hospital \\ 3 Department of Psychology, Boston College \\ ${ }^{4}$ Department of Psychology, Harvard University
}

\begin{abstract}
Aging impacts memory formation and the engagement of frontal and medial temporal regions. However, much of the research to date has focused on the encoding of neutral verbal and visual information. The present fMRI study investigated age differences in a social encoding task while participants made judgments about the self or another person. Although previous studies identified an intact self-reference effect with age, subserved by robust engagement of medial prefrontal cortex (mPFC) by both young and older adults, we identified a number of age differences. In regions including superior $\mathrm{mPFC}$, inferior prefrontal cortex, and anterior and posterior cingulate cortex, young and older adults exhibited reversals in the pattern of activity for self and other conditions. Whereas young primarily evidenced subsequent forgetting effects in the self-reference condition, older adults demonstrated subsequent memory effects in the other-reference condition. These results indicate fundamental differences across the age groups in the engagement of elaborative encoding processes. We suggest that older adults may encode information about the self in a more normative manner, whereas young adults focus on encoding the unique aspects of the self and distinguishing the self from others.
\end{abstract}

\section{Keywords}

Aging; self; long-term memory; prefrontal cortex; cognition; fMRI

\begin{abstract}
Declines in long-term memory function are a common complaint for even healthy populations of older adults, and neuroimaging has begun to reveal information about the effects of aging on the brain regions implicated in memory formation. In young adults, the initial encoding of information into memory activates a network of regions, including inferior frontal and medial temporal gyri (Brewer et al., 1998; Kirchhoff et al., 2000; Wagner et al., 1998). Although these same regions contribute to encoding processes in older adults (Daselaar et al., 2003; Morcom, Good, Frackowiak, \& Rugg, 2003), aging reduces the activation of medial temporal gyrus (Dennis, Daselaar, \& Cabeza, 2007; Gutchess et al., 2005) and the deactivation of medial parietal cortex (Miller et al., 2008), regions that have been implicated in memory formation
\end{abstract}

(C) 2009 Elsevier Ltd. All rights reserved.

Correspondence concerning this article should be addressed to: Dr. Angela Gutchess Department of Psychology Brandeis University 415 South Street, MS 062 Waltham, MA 02454-9110 gutchess@ brandeis.edu phone: (781) 736-3247 fax: (781) 736-3291.

Publisher's Disclaimer: This is a PDF file of an unedited manuscript that has been accepted for publication. As a service to our customers we are providing this early version of the manuscript. The manuscript will undergo copyediting, typesetting, and review of the resulting proof before it is published in its final citable form. Please note that during the production process errors may be discovered which could affect the content, and all legal disclaimers that apply to the journal pertain. 
under some conditions. Furthermore, older adults recruit additional regions, particularly in prefrontal cortex, that do not contribute to successful encoding of information in young adults (Dennis, Daselaar, et al., 2007; Gutchess et al., 2005; Kensinger \& Schacter, 2008). Even when similar regions are engaged by younger and older adults during the formation of true and false memories, the regions are engaged to a different extent across the age groups based on the amount of information later retrieved (Dennis, Kim, \& Cabeza, 2007).

While many studies reveal some changes to the encoding network (e.g., Dennis, Daselaar, et al., 2007; Gutchess et al., 2005; Miller et al., 2008) in older adults, these studies of successful encoding have focused almost exclusively on the encoding of relatively neutral verbal and visual information. In contrast, research in young adults suggests that the core encoding network of inferior prefrontal and medial temporal regions is augmented for the encoding of specific types of information. For example, encoding of emotional information engages the amygdala whereas the encoding of social information recruits dorsomedial and orbital prefrontal cortex (Harvey, Fossati, \& Lepage, 2007; LaBar \& Cabeza, 2006).

One study that investigates the effects of aging on the formation of emotional memories implicates roles for the amygdala, fusiform gyrus, and orbitofrontal cortex in both age groups (Kensinger \& Schacter, 2008). Age differences emerge, however, for the encoding of positive information, with older adults activating medial prefrontal cortex (mPFC) and the cingulate gyrus to a greater extent than young. These results suggest that investigating the effects of aging across a broad range of modalities and stimuli may reveal a more complex pattern of preserved function and change in the encoding network than has been identified in the study of more neutral, typically verbal, materials.

Though no study has examined whether aging affects the neural processes that correspond with memory for information processed in a self-referential fashion, the supporting neural substrates have been well-characterized for young adults. Information that is related to the self at encoding engages medial prefrontal cortex (mPFC), with higher levels of activity for self-referenced information that is later remembered compared to that which is later forgotten (Macrae, Moran, Heatherton, Banfield, \& Kelley, 2004). Although mPFC underlies successful encoding of selfrelevant information in young adults, it does so in conjunction with a number of other regions, including parahippocampal gyrus and anterior prefrontal cortex, regions that are not engaged when simply reflecting on qualities that describe oneself or another person. Recent studies of the effects of aging suggest that older adults benefit much like young adults from a selfreferencing strategy (Gutchess, Kensinger, Yoon, \& Schacter, 2007), and that both groups similarly activate $\mathrm{mPFC}$ when thinking about oneself compared to thinking about another person (Gutchess, Kensinger, \& Schacter, 2007). The extent to which aging impacts the role of $\mathrm{mPFC}$ and the broader neural network implicated in the successful encoding of self-

referenced information has not been established. The present study investigates whether aging is associated with reorganization of memory networks for social information, specifically selfreferenced information.

The study of self-referencing also offers an opportunity to test the extent to which aging reduces the specificity of the neural response. In ventral visual cortex, including the fusiform face area and the parahippocampal place area, young exhibit striking specificity in the neural response to particular categories of items, such as faces, places, or body parts (see Kanwisher \& Yovel, 2006 for a review), but older adults exhibit less category selectivity during the passive viewing of pictures of single objects (Park et al., 2004). During viewing of complex scenes consisting of a focal object in a meaningful background, older adults, relative to young, show a diminished response in object-selective regions, although the response of background-selective regions does not differ across the age groups (Chee et al., 2006). 
A different pattern that reflects a loss of specificity with age is increased bilaterality. As documented by a number of studies (see Cabeza, 2002; Reuter-Lorenz \& Lustig, 2005 for reviews), older adults tend to recruit two hemispheres to complete tasks for which young recruit a single hemisphere. Whereas young show a strong lateralization in prefrontal (PFC) cortex for working memory function with verbal materials engaging left PFC and spatial materials engaging right $\mathrm{PFC}$, both types of materials engage both hemispheres in older adults (ReuterLorenz et al., 2000). While the reduced specificity in ventral visual cortex appears to reflect a loss of function with age, the reduced hemispheric specificity in prefrontal cortex has been interpreted as serving a compensatory function, with older adults engaging additional resources to help them perform cognitively challenging tasks.

Thus far, the examination of age-related changes in the neural response during passive viewing of specific classes of stimuli has been restricted largely to the visual domain and age differences in bilaterality have been identified primarily during effortful cognitive tasks. Social information represents another domain that is highly specialized for young adults, particularly in the neural response to thinking about oneself compared to thinking about other people.

MPFC is engaged more by self judgments, whereas left inferior frontal cortex is engaged more by judgments about others (Craik et al., 1999; Kelley et al., 2002). Our evidence that older and younger adults similarly engage $\mathrm{mPFC}$ for self judgments relative to other person judgments (Gutchess, Kensinger, \& Schacter, 2007) suggests that the specificity of the neural response for self-relevant information is preserved with age. However, because the age groups were compared on a relatively simple adjective judgment task, our analyses may not have been the strongest test for age differences in mPFC recruitment. It is possible that the specificity of the neural response to self-referencing on the adjective judgment task will break down for older adults under more resource-demanding conditions, such as those required to encode information successfully into memory. Although we did not manipulate resource demands within the present study, we suggest that encoding draws on more resource-demanding processes than our previous comparison of self- vs. other-referencing (Gutchess et al., 2007). The present study serves as a further test of the specificity of the response of MPFC with age.

To address questions regarding the effects of aging on the activity of regions associated with memory formation and the domain-specificity of neural responses, the present study adopted a subsequent memory approach (Brewer et al., 1998; Wagner et al., 1998). Neural activity was compared for encoding trials separated based on participants' later ability to remember or forget that they previously studied the word. To investigate the effects of aging on encoding activity related to self-referencing, trials for which young and older adults made self-reference decisions were compared to trials for which participants made these judgments about another person.

\section{METHODS}

\section{Participants}

Seventeen young (ages 18-28; $M=23.24, \mathrm{SD}=2.63 ; 8$ females) and fifteen older (ages 61-80; $M=71.60, \mathrm{SD}=4.55 ; 11$ females) adults participated in the study in exchange for payment. These participants represent a subgroup of the participants reported in Gutchess, Kensinger, \& Schacter (2007); four additional participants were excluded for having insufficient trials (< 5 ) in each condition. Otherwise, the same exclusion and inclusion criteria apply for all subjects. Participants provided written informed consent for a protocol approved by Massachusetts General Hospital and Harvard University. 


\section{Materials and Procedure}

Participants encoded 144 adjectives, based on the lists created by Craik et al. (1999). For each encoding trial, participants made a yes/no button press to indicate their response for one of three orienting conditions indicated for that trial: self (i.e., does this adjective describe me?), other (i.e., does this adjective describe Albert Einstein?), or case (i.e., is this adjective presented in upper case?). The other person condition provided a socially meaning comparison for the self condition that was likely to engage distinct brain regions (Kelley et al., 2002), while the case condition was intended to provide a shallow, perceptual judgment that would not be semantically or personally meaningful. The selection of Albert Einstein for the other person was based on prior research establishing that younger and older adults similarly rated him as familiar and viewed him with positive regard (Gutchess, Kensinger, Yoon, \& Schacter, 2007). Trials and baseline fixations were pseudorandomly ordered in a jittered design (Dale, 1999). The study was presented using E-Prime software (Psychology Software Tools, Pittsburgh, PA) and three counterbalanced lists rotated the assignment of adjectives to each condition across subjects. After an approximately fifteen minute delay, participants received a surprise recognition test outside of the scanner. For 288 adjective trials, participants decided whether or not they'd encoded each word previously in the study, and used labeled keys to make a "yes" or "no" keypress. 144 of the adjectives, 48 in each of the three conditions, had been studied previously, and 144 of the adjectives were presented for the first time at recognition. Upon making a recognition decision, participants were instructed to respond quickly, but they were also permitted to take breaks during the self-paced recognition test.

\section{Neuropsychological Measures}

To characterize the subject samples, participants. completed measures of demographics, health, vocabulary (Shipley, 1986), and speed of processing (Digit Comparison; Hedden et al., 2002). All participants scored at least a 28 on the Mini-Mental State Examination (MMSE), which was used to screen for orientation (Folstein, Folstein, \& McHugh, 1975). Performance on neuropsychological measures is presented in Table 1. Results indicate that our samples are typical of studies with high-functioning older adults. The older adults group is relatively select, with similar educational attainment as young adults, a trend for higher vocabulary scores, and good self-reported health, relative to same-age peers. Older adults perform poorer than young on the speed of processing measure, which is a robust finding for cognitive aging studies (Salthouse, 1996).

\section{Image acquisition and data analysis}

An echo-planar imaging (EPI) sequence (TR $=2000 \mathrm{~ms}, \mathrm{TE}=30 \mathrm{~ms}, \mathrm{FOV}=200 \mathrm{~mm}$, flip angle $=90^{\circ}$ ) was used to acquire slices oriented to the AC/PC, using a Siemens Allegra 3T scanner (Erlangen, Germany). Thirty images, $3.2 \mathrm{~mm}$ thick with a $3 \mathrm{~mm}$ skip, were acquired over two runs, each consisting of 216 TRs. A high-resolution anatomical image was also acquired, using an MP-RAGE sequence.

Pre-processing consisted of slice-time correction, realignment to correct for motion, normalization to the Montreal Neurological Institute template, resampling to 2-mm cubic voxels, and spatial smoothing to a 6-mm full-width half maximum isotropic Gaussian kernel. SPM2 (Wellcome Department of Cognitive Neurology, London, UK) software was used for preprocessing and data analysis.

For data analysis, we used a subsequent memory event-related design, in which encoding events were sorted based on the participant's response on the later memory test. Encoded adjectives could be either successfully remembered (i.e., "yes" response) or forgotten (i.e., "no" response) at the time of recognition. Thus, six regressors were included in the model: Self-remembered, Self-forgotten, Other-remembered, Other-forgotten, Case-remembered, and 
Case-forgotten. For each of the two runs, session regressors were included. Events were convolved with a canonical hemodynamic response function. Contrast images were smoothed with an 8-mm full-width half maximum isotropic Gaussian kernel, for a total of $10 \mathrm{~mm}$ of smoothing across the two stages. To compare activity associated with successful encoding in the self condition, over and above the activity during successful encoding in the other person condition, we created contrasts with the following subtraction: [Self-remembered - Selfforgotten] - [Other-remembered - Other-forgotten]. Contrasts for young and older adults were compared in a random-effects group analysis, and two-sample t-tests had a threshold of $\mathrm{p}<$. 001 (uncorrected) and an extent threshold of 20 voxels. We extracted the percent signal change from regions of interest using MarsBaR software (Brett, Anton, Valabregue, \& Poline, 2002). These estimates were extracted from spheres with a $6 \mathrm{~mm}$ radius, centered around the peak coordinates, and averaged across the $3^{\text {rd }}-6^{\text {th }}$ time points. To assess regions of activity in common for young and older adults, a mask of voxels significant at $p<.01$ with no voxel extent threshold was created for one age group and used to test for overlapping regions of activation in the second group, for a conjoint probability of $p<.001$ using Fisher's method (Fisher, 1950; Lazar, Luna, Sweeney, \& Eddy, 2002).

\section{RESULTS}

\section{Behavioral Recognition Performance}

We compared corrected recognition scores (hit minus false alarms) in a mixed ANOVA with Condition (self/other/case) as a within-subject variable and Age (young/elderly) as a betweengroup variable. The results revealed a main effect of condition $\mathrm{F}(2,60)=108.07, \mathrm{p}<.001$, $\eta_{\mathrm{p}}{ }^{2}=.78$. Follow-up $2 \times 2$ ANOVAs with only two levels of the condition variable (Self vs. Other and Other vs. Case) revealed higher recognition accuracy in the self condition than the other condition, $\mathrm{F}(1,30)=23.17, \mathrm{p}<.001, \eta_{\mathrm{p}}^{2}=.44$, and higher recognition accuracy in the other condition than the case condition, $F(1,30)=106.24, p<.001, \eta_{p}^{2}=.78$. See Figure 1 . Across all levels of the condition variable, there was a main effect of age, $F(1,30)=8.26, \mathrm{p}<$. $01, \eta_{\mathrm{p}}{ }^{2}=.22$, with young correctly recognizing more adjectives than elderly. Despite the age difference in the overall level of performance, the pattern of the conditions was equivalent for young and elderly with no interaction of condition $\times$ age $\left(F<1, \eta_{\mathrm{p}}{ }^{2}=.01\right)$. The pattern of results converges with previous studies comparing self-referencing in young and older adults (Glisky \& Marquine, 2009; Gutchess, Kensinger, Yoon, \& Schacter, 2007; Mueller, Wonderlich, \& Dugan, 1986).

Analyzing the hit and false alarm rates separately suggests that the age differences in the corrected recognition scores reflect the combination of both scores. Age differences in the hit rates did not approach significance in any condition $\left(t_{\mathrm{s}}<1\right)$. While the false alarm rate was slightly higher for older adults $(M=.24)$ than young $(M=.19)$, the difference was not significant, $t(30)=1.26, p=.22$. Note that because there was a single pool of lure items, a single false alarm rate was used for each subject to correct the hit rates for each condition.

\section{Functional MRI Data}

Analyses of Subsequent Memory for Self- vs. Other-Referenced Trials: In an analysis of common activity in young and older adults, no regions were significant. This was also true at a more lenient statistical level of $\mathrm{p}<.0025$ (i.e., with the mask for each age group thresholded at $\mathrm{p}<.05$ ). This contrasts our previous finding of robust common activation across younger and older adults during judgments of self vs. other when the success of encoding is not considered (Gutchess, Kensinger, \& Schacter, 2007).

As shown in Table 2, a number of regions emerged as exhibiting age differences in the interaction of Self/Other $\times$ Remembered/Forgotten. This interaction analysis identified regions 
that differentially responded during the successful encoding of self-referenced items and otherreferenced items, and on which young and older adults differed. In order to understand the differences in activity across age groups (young and older adults) and conditions (self and other), we compared the pattern of activity for Remembered - Forgotten trials for regions that were of interest based on prior literature. We selected mPFC due to the involvement of the region in self-referencing; although these effects tend to be localized in a more ventral region of mPFC, superior regions emerge when considering the self or other people, under some conditions (Mitchell, Macrae, \& Banaji, 2004;2006). Posterior cingulate (PCC) is involved in both self-referential (Kelley et al., 2002;Johnson et al., 2006) and memory-related processes (Wagner, Shannon, Kahn, \& Buckner, 2005), including subsequent forgetting effects (Wagner \& Davachi, 2001). ACC responds to self and other, relative to a nonsemantic comparison condition (Kelley et al., 2002) and also exhibits age-related differences in its response to conflict (Milham et al., 2002) and under challenging memory conditions (Gutchess, Hebrank, et al., 2007), perhaps reflecting cognitive resource limitations with age (Persson et al., 2004). ACC and PCC both are modulated in response to an individual's goals and regulatory focus during self-reflection tasks (Touryan et al., 2007), processes which could impact memory and differ across age groups. Inferior frontal gyrus has been implicated in a number of studies of encoding processes (e.g., Brewer et al., 1998;Kirchhoff et al., 2000;Wagner et al., 1998) and often exhibits age-related change, specifically in terms of decreased activation of the left hemisphere with age (e.g., Logan, Sanders, Snyder, Morris, \& Buckner, 2002;Lustig et al., 2003; Persson et al., 2004). These regions and their response to our tasks are displayed in Figure 2.

For all of the selected regions, the graphs suggest that age differences in self-referencing during encoding result from reversals in the pattern of activity across the two age groups, rather than a failure of one group to differentially engage the regions for successful vs. unsuccessful encoding of self trials. For young adults, the four regions of interest show subsequent forgetting effects, with the regions engaged relatively more for subsequently forgotten items than subsequently remembered self-referenced trials (e.g., the bars in Figure 2 are negative-going). In analyses of only the young adults, the subsequent forgetting effects reach significance at the $\mathrm{p}<.001$ threshold in the left inferior frontal and left superior mPFC regions and the anterior and right posterior cingulate regions emerge at the $p<.005$ level of significance. By contrast, young adults tended to showed the opposite (though non-significant) pattern of response in the anterior cingulate and medial prefrontal cortex for the other-referenced trials, with greater activity for subsequently remembered than subsequently forgotten items.

In contrast to the young adults, older adults show subsequent memory effects in each of these regions for the self-referenced items, and subsequent forgetting effects for the other-referenced items. This pattern is substantiated by an analysis of older adults alone, thresholded at $\mathrm{p}<.001$, in which these regions emerge, with the exception of superior mPFC. However, a region within $2 \mathrm{~mm}$ of the superior mPFC peak voxel emerges in the analysis of self remembered - self forgotten at the $\mathrm{p}<.005$ level of significance. See Supplemental Figure 1 for separate displays of percent signal change for remembered and forgotten trials.

Notably, the results seem to be driven by age differences in self-referencing rather than reflecting higher-order interactions with the other person condition. In an analysis of self remembered minus forgotten trials only, age differences emerge in the majority of regions, including the regions of interest displayed in Figure 2 (see the rightmost column in Table 2).

${ }^{1}$ Thus, the reversal from subsequent forgetting effects in the young to subsequent remembering effects in the older adults is present for most regions, regardless of the pattern evident for the other person trials.

\footnotetext{
${ }^{1}$ Results from the comparison of Self Remembered and Self Forgotten trials are available from the authors.
} 
Despite young adults' superior memory for self-referenced information relative to otherreferenced information, the regions discussed thus far do not reveal mechanisms that support successful encoding of self-referenced information. As discussed, subsequent memory effects were pronounced in older, but not young, adults. To identify potential mechanisms that respond more strongly for self than other referencing, we contrasted self-remembered to otherremembered trials in young and older adults. As shown in Table 3, young and older adults both engage regions of ventromedial prefrontal cortex (vmPFC), ACC, and middle temporal cortex. Older adults alone exhibit activation in these regions, as well as number of other regions including superior prefrontal cortex and a more posterior region of the cingulate extending into the precuneus. In the young adults alone, activation of ACC and superior temporal cortex reach significance, suggesting mechanisms for the successful encoding of self-referenced information in the presence of other-referenced information. Although regions identified in this analysis are not selective to memory processes (in contrast with the analysis that includes forgotten items), the analysis identifies regions that young adults recruit more than older adults in order to distinguish self from other. It is possible, however, that these regions contribute to memory processes because these regions did not emerge in the overall comparison of self vs. other trials without regard to memory (Gutchess et al., 2007).

Medial Prefrontal (mPFC) ROI Analysis: Although vmPFC did not emerge in the comparison of self/other $\times$ remembered/forgotten across age groups, previous investigations found greater activity in this region for subsequently recognized items (Macrae et al., 2004). Thus, we probed vmPFC as a region of interest using the peak from our comparison of self vs. other judgments (Gutchess, Kensinger, \& Schacter, 2007). The pattern of the means was consistent with prior findings, with slightly higher activity for self-remembered compared to self-forgotten trials and little difference in activity between other-remembered and otherforgotten trials ${ }^{2}$. The pattern was the same across age groups and if anything, older adults may have differentiated between self-remembered and self-forgotten slightly more than young. However, none of the trends involving age or subsequent memory were borne out statistically.

\section{DISCUSSION}

We observed widespread effects of aging on subsequent memory for self-referenced information, relative to other-referenced information. Previous studies examining subsequent memory for nonsocial information report age differences in a variety of regions including prefrontal, medial temporal, and parietal cortices. The age differences in these studies tend to be relatively focal and, although older adults may activate regions of prefrontal cortex more than young (Dennis, Daselaar, et al., 2007; Gutchess et al., 2005; Kensinger \& Schacter, 2008), the more common pattern is one of greater activation, or deactivation, for younger than older adults (Daselaar et al., 2003; Dennis, Daselaar, et al., 2007; Gutchess et al., 2005; Miller et al., 2008). The nature of our results is surprising because older adults show greater differences than young during self-referencing in widespread regions, and the pattern of activity in some regions reverses with age. As seen in Figure 2, young adults exhibit subsequent forgetting effects for self-referenced information in anterior and posterior cingulate, and superior and inferior frontal regions. Previous research identified only subsequent memory effects. Older adults, in contrast, tend to show subsequent remembering effects in these same regions. Considering the other person condition suggests even more complex findings, with other person judgments tending to show the reverse pattern of the self judgments (i.e., if the region exhibits a subsequent forgetting effect for self, it tends to exhibit a subsequent memory effect for other) and younger and older adults again contrasting each other (i.e., one group exhibits subsequent memory effects, the other group shows subsequent forgetting effects).

\footnotetext{
${ }^{2}$ Results available from the authors.
} 
As discussed in the literature, subsequent forgetting effects may reflect failures to engage encoding-related processes or to disengage from internal processes that disrupt attentiondemanding tasks (Otten \& Rugg, 2001; Wagner \& Davachi, 2001). It seems surprising, then, that young adults exhibit greater subsequent forgetting effects than older adults, who are known to experience greater difficulty inhibiting irrelevant processes (Hasher \& Zacks, 1988). However, subsequent forgetting effects can also reflect the reallocation of resources in ways that support successful task performance (Daselaar, Prince, \& Cabeza, 2004), an explanation that may be more consistent with greater effects in the young adults.

While several studies identify difficulty in deactivating regions with age (e.g., Grady, Springer, Hongwanishkul, McIntosh, \& Winocur, 2006; Miller et al., 2008; Persson, Lustig, Nelson, \& Reuter-Lorenz, 2007), our finding of reversals in which conditions engage a region across the age groups is less common. This finding may at first seem perplexing; however, our study is one of the first to contrast multiple encoding tasks in a subsequent memory design with age and this design feature could shape our results in a few distinct ways. Our results could suggest fundamental differences in the way that individuals encode information about self and others across age groups. Older adults could engage elaborative processes that benefit memory for the self but young adults may engage the same elaborative encoding processes to encode information about other people. For example, older adults could consider the self in a more normative manner, thinking about the traits they possess that are shared with many people. Young adults could adopt a similar approach when making judgments about Albert Einstein, but when making self-referential judgments, they could focus on the unique aspects of their personalities. Evaluating others who are similar or dissimilar to oneself activates distinct regions of $\mathrm{mPFC}$, with similar others engaging the ventral portion of $\mathrm{mPFC}$ typically engaged for judgments of the self and dissimilar others activating a more dorsal mPFC region (Mitchell et al., 2006). Our dorsal mPFC activation, depicted in Figure 2B, is close to that identified by Mitchell et al. (2006), and is present for subsequent memory for other person judgments in the young adults but for subsequent memory of self judgments in the older adults, consistent with our suggestion for age differences in elaborative encoding processes. Evidence for overall age differences in the processes engaged during self-referential judgments did not emerge in our previous study (Gutchess, Kensinger, \& Schacter, 2007) but perhaps the age groups differ only for the trials on which additional elaborative processes are engaged to support encoding.

Another possible explanation is that there may have been some interference across task conditions. Because conditions were intermixed in a pseudorandom design, the task might require considerable monitoring and attention to the task, and it is possible that participants initially referenced the incorrect target on some trials. For example, when prompted to judge whether or not a word described another person, participants could have initially attended to whether the word was self-relevant. These initial errors in orientation could have impacted later memory for the word, leading to forgetting. Younger and older adults could be differentially subject to these types of errors, consistent with findings of inhibitory deficits with age (Hasher \& Zacks, 1988). The involvement of ACC and PCC, implicated in conflict detection (Carter \& van Veen, 2007) and monitoring the internal environment (Gusnard \& Raichle, 2001), respectively, could support a case for interference. The heightened activation of ACC when judging that a word does not describe oneself (Macrae et al., 2004) suggests that the region may also respond to conflict during self-referencing tasks. While differences in interference across conditions could contribute in part to the pattern of results, it seems unlikely to fully account for the pattern of data. Interference could explain a main effect of age, but would be predicted to affect both the self or other person conditions rather than disproportionately affecting one over the other. An alternative possibility is that potential interference between conditions actually reflects age differences in the concepts of self and other, with older adults making more normative judgments of the self that, implicitly or explicitly, reference other people. It is important to note that we are not suggesting that older 
adults were unable to perform the task. Accuracy is high in the case condition, the only condition with an objectively accurate answer, with both groups performing with greater than $94 \%$ accuracy $^{3}$ and no significant age differences.

While age differences in interference across task conditions could operate in conjunction with other mechanisms, our suggestion of age differences in the elaborative encoding processes that support self- and other- referencing is the most parsimonious explanation at present. Because previous studies (Macrae et al., 2004) of subsequent memory for the self included only selfreference trials and did not find subsequent forgetting effects, we suggest that the inclusion of multiple conditions contributes to the pattern of data that emerges in our study for young adults alone. Appropriate designs are needed to further explore the nature of these effects and to tease apart the underlying processes occurring in young adults alone, as well as across age groups.

Aside from exploring age differences in the memory encoding network as a function of the social and self-relevant nature of stimuli, a second aim of the study was to assess the degree to which the specificity of the mPFC response to social information was intact with age. Previous studies have identified a loss of specificity in ventral visual regions with age (Park et al., 2004) and we questioned whether this same finding would extend to the specialized domain of social processes with age. While our exploratory analyses suggest that the mPFC response is selectively enhanced for self relative to other (as reported in Gutchess, Kensinger, \& Schacter, 2007), and particularly when the self-referenced information is later remembered, the region did not emerge in our random effects analyses. While the pattern of data is generally supportive, it requires further substantiation through a study with greater power.

Low power is a potential limitation of the present study. Participants' relatively high recognition performance in the self condition resulted in small bins of self-forgotten items $(\mathrm{M}=14.12$ for the young adults and $\mathrm{M}=16.27$ for the older adults). However, the reported results seem to be robust. In a subsample of thirteen young and fourteen elderly participants who had at least 10 items in each bin, a threshold consistent with previous studies (Harvey et al., 2007; Kensinger $\&$ Schacter, 2007), the results from the regions of interest are consistent with those displayed in Figure $2^{4}$. Future investigations with more trials will be needed to assess whether age differences in the engagement of neural regions occur during successful encoding of selfreferenced information, which would complement our findings of age differences primarily in subsequent forgetting effects. An additional concern is whether our study design is more robust for one age group than the other. In a subsequent memory design, trials are assigned to conditions based on each participant's distribution of responses, which could introduce systematic differences in the design across the age groups. If the designs tend to be more robust for one age group than the other, this could explain the tendency for significant subsequent memory effects in the older, but not younger, group. However, analyses of design efficiency (Smith, Jenkinson, Beckmann, Miller, \& Woolrich, 2007) do not reveal significant age differences for either of our random effects analyses ${ }^{5}$.

The limited number of trials also prevented us from examining other questions of interest, such as the potential for age differences in the elaborative encoding processes for adjectives endorsed as describing oneself (or another person) compared to those that did not describe the target individual. Ventral MPFC and ACC differentially respond during "yes" and "no" responses during self-referencing (Macrae et al., 2004; Moran, Macrae, Heatherton, Wyland, $\&$ Kelley, 2006). Although robust age differences did not emerge in the behavioral frequency

\footnotetext{
${ }^{3}$ Note that one older adult was excluded from this analysis because she used one response key throughout the study, likely reflecting mis-placement of her fingers on the response pad.

${ }^{4}$ Results available from the authors.

${ }^{5}$ Results available from the authors.
} 
of "yes" vs. "no" responses or in the neural activity during self-referencing (Gutchess et al., 2007), age differences could be selective to engaging neural regions during the successful encoding of these different types of items. It is possible that our finding of age differences in regions of ACC reflect, to some extent, the contribution of endorsing an item as self-descriptive, but we lack the power to contrast "yes" and "no" responses. Future studies will be needed to fully address this question.

In conclusion, aging alters the neural activity associated with the successful formation of memories for self-referenced information. Despite relative preservation of the regions engaged during self-referential processing (Gutchess, Kensinger, \& Schacter, 2007), there are fundamental age differences in the regions tied to successful encoding of self-referenced information. Thus, though young and older adults both engage a similar network of regions during self-referential processing, the function that the regions play in modulating memory formation appears to be altered with aging. Whereas young exhibit subsequent forgetting effects in prefrontal and parietal regions, older adults tend to show subsequent memory effects in these same regions. Because of this reversal in the pattern of activity across the age groups, these changes do not seem to reflect simple age-related cognitive declines or even compensatory mechanisms. Rather, younger and older adults differ in the elaborative encoding processes engaged for self- and other-referencing. Future studies will be needed to assess the extent to which the inclusion of multiple, intermixed trial types contributes to these results. In contrast to our previous finding that young and elderly similarly engage regions implicated in self-referencing, the present data suggests that widespread age differences emerge when memories are formed while referencing the self or another person. The findings are consistent with previous literature that suggests age-related changes in the activation of regions guiding memory formation. These age differences emerge even for social information, and in spite of the effectiveness of self-referencing as a strategy to support encoding.

\section{Supplementary Material}

Refer to Web version on PubMed Central for supplementary material.

\section{Acknowledgments}

The authors gratefully acknowledge support from the National Institutes of Health, grants AG008441 (to D.L.S.), AG026920 (to A.H.G.), and MH070199 (to E.A.K.). Portions of this research were conducted while A.H.G. was an AFAR Research Grant recipient. The Athinoula A. Martinos Center for Biomedical Imaging is supported by the National Center for Research Resources (grant P41 RR14075) and by the MIND Institute. We thank Alana Wong, Gina Gotthilf, and Roee Gilron for experimental assistance, and Moshe Bar, Malia Mason, and Gagan Wig for helpful discussions.

\section{References}

Brewer JB, Zhao Z, Desmond JE, Glover GH, Gabrieli JDE. Making memories: Brain activity that predicts how well visual experience will be remembered. Science 1998;281:1185-1187. [PubMed: 9712581]

Brett, M.; Anton, J-L.; Valabregue, R.; Poline, J-B. Region of interest analysis using an SPM toolbox; Paper presented at the 8th International Conference on Functional Mapping of the Human Brain; Sendai, Japan. 2002.

Cabeza R. Hemispheric asymmetry reduction in older adults: The HAROLD model. Psychology and Aging 2002;17:85-100. [PubMed: 11931290]

Carter CS, van Veen V. Anterior cingulate cortex and conflict detection: An update of theory and data. Cognitive, Affective, and Behavioral Neuroscience 2007;7:367-379.

Chee MWL, Goh JOS, Venkatraman V, Tan JC, Gutchess A, Sutton B, Hebrank A, Leshikar E, Park D. Age-related changes in object processing and contextual binding revealed using fMR-Adaptation. Journal of Cognitive Neuroscience 2006;18:495-507. [PubMed: 16768356] 
Craik FIM, Moroz TM, Moscovitch M, Stuss DT, Winocur G, Tulving E, Kapur S. In search of the self: A positron emission tomography study. Psychological Science 1999;10:26-34.

Dale AM. Optimal experimental design for event-related fMRI. Human Brain Mapping 1999;8:109-114. [PubMed: 10524601]

Daselaar SM, Prince SE, Cabeza R. When less means more: Deactivations during encoding that predict subsequent memory. NeuroImage 2004;23:921-927. [PubMed: 15528092]

Daselaar SM, Veltman DJ, Rombouts SA, Lazeron RH, Raaijmakers JG, Jonker C. Neuroanatomical correlates of episodic encoding and retrieval in young and elderly subjects. Brain 2003;126:43-56. [PubMed: 12477696]

Dennis NA, Daselaar S, Cabeza R. Effects of aging on transient and sustained successful memory encoding activity. Neurobiology of Aging 2007;28:1749-1758. [PubMed: 16919850]

Dennis NA, Kim H, Cabeza R. Effects of aging on true and false memory formation: An fMRI study. Neuropsychologia 2007;45:3157-3166. [PubMed: 17716696]

Fisher, RA. Statistical methods for research workers. Oliver \& Boyd; London: 1950.

Folstein MF, Folstein SE, McHugh PR. Mini-mental state: A practical method for grading the cognitive state of patients for the clinician. Journal of Psychiatric Research 1975;12:189-198. [PubMed: 1202204]

Glisky EL, Marquine MJ. Semantic and self-referential processing of positive and negative trait adjectives in older adults. Memory 2009;17:144-157. [PubMed: 18608973]

Grady CL, Springer MV, Hongwanishkul D, McIntosh AR, Winocur G. Age-related changes in brain activity across the adult lifespan. Journal of Cognitive Neuroscience 2006;18:227-241. [PubMed: 16494683]

Gusnard DA, Raichle ME. Searching for a baseline: Functional imaging and the resting human brain. Nature Reviews Neuroscience 2001;2:685-694.

Gutchess AH, Hebrank A, Sutton B, Leshikar E, Chee MWL, Tan JC, Goh JOS, Park DC. Contextual interference in recognition memory with age. NeuroImage 2007;35:1338-1347. [PubMed: 17355910]

Gutchess AH, Kensinger EA, Schacter DL. Aging, self-referencing, and medial prefrontal cortex. Social Neuroscience 2007;2:117-133. [PubMed: 18633811]

Gutchess AH, Kensinger EA, Yoon C, Schacter DL. Ageing and the self-reference effect in memory. Memory 2007;15:822-837. [PubMed: 18033620]

Gutchess AH, Welsh RC, Hedden T, Bangert A, Minear M, Liu L, Park DC. Aging and the neural correlates of successful picture encoding: Frontal activations compensate for decreased medial temporal activity. Journal of Cognitive Neuroscience 2005;17:86-95.

Hasher, L.; Zacks, RT. Working memory, comprehension, and aging: A review and new view. In: Bower, GH., editor. The psychology of learning and motivation. Vol. 22. Academic Press; San Diego, CA: 1988. p. 193-225.

Harvey P-O, Fossati P, Lepage M. Modulation of memory formation by stimulus content: Specific role of the medial prefrontal cortex in the successful encoding of social pictures. Journal of Cognitive Neuroscience 2007;19:351-362. [PubMed: 17280522]

Hedden T, Park DC, Nisbett R, Ji L-J, Jing Q, Jiao S. Cultural variation in verbal versus spatial neuropsychological function across the life span. Neuropsychology 2002;16:65-73. [PubMed: 11853358]

Johnson MK, Raye CL, Mitchell KJ, Touryan SR, Greene EJ, Nolen-Hoeksema S. Dissociating medial frontal and posterior cingulate activity during self-reflection. Social Cognitive and Affective Neuroscience 2006;1:56-64. [PubMed: 18574518]

Kanwisher N, Yovel G. The fusiform face area: A cortical region specialized for the perception of faces. Philosophical Transactions of the Royal Society 2006;361:2109-2128.

Kelley WM, Macrae CN, Wyland CL, Caglar S, Inati S, Heatherton TF. Finding the self? An eventrelated fMRI study. Journal of Cognitive Neuroscience 2002;14:785-794. [PubMed: 12167262]

Kensinger EA, Schacter DL. Remembering the specific visual details of presented objects: Neuroimaging evidence for effects of emotion. Neuropsychologia 2007;45:2951-2962. [PubMed: 17631361] 
Kensinger EA, Schacter DL. Neural processes supporting young and older adults' emotional memories. Journal of Cognitive Neuroscience 2008;20:1161-1173. [PubMed: 18284340]

Kirchhoff BA, Wagner AD, Maril A, Stern CE. Prefrontal-temporal circuitry for episodic encoding and subsequent memory. The Journal of Neuroscience 2000;20:6173-6180. [PubMed: 10934267]

LaBar KS, Cabeza R. Cognitive neuroscience of emotional memory. Nature Reviews Neuroscience 2006;7:54-64.

Lazar NA, Luna B, Sweeney JA, Eddy WF. Combining brains: A survey of methods for statistical pooling of information. NeuroImage 2002;16:538-550. [PubMed: 12030836]

Logan JM, Sanders AL, Snyder AZ, Morris JC, Buckner RL. Under-recruitment and non-selective recruitment: Dissociable neural mechanisms associated with aging. Neuron 2002;33:827-840. [PubMed: 11879658]

Lustig C, Snyder AZ, Bhakta M, O'Brien K, McAvoy M, Raichle ME, Morris JC, Buckner RL. Functional deactivations: Change with age and dementia of the Alzheimer type. Proceedings of the National Academy of Sciences of the United States of America 2003;100:14504-14509. [PubMed: 14608034]

Macrae CN, Moran JM, Heatherton TF, Banfield JF, Kelley WM. Medial prefrontal activity predicts memory for self. Cerebral Cortex 2004;14:647-654. [PubMed: 15084488]

Milham MP, Erickson KI, Banich MT, Kramer AF, Webb A, Wszalek T, Cohen NJ. Attentional control in the aging brain: Insights from an fMRI study of the Stroop task. Brain \& Cognition 2002;49:277296. [PubMed: 12139955]

Miller SL, Celone K, DePeau K, Diamond E, Dickerson BC, Rentz D, Pihlajamäki M, Sperling RA. Agerelated memory impairment associated with loss of parietal deactivation but preserved hippocampal activation. Proceedings of the National Academy of Sciences USA 2008;105:2181-2186.

Mitchell JP, Macrae CN, Banaji MR. Encoding-specific effects of social cognition on the neural correlates of subsequent memory. The Journal of Neuroscience 2004;24:4912-4917. [PubMed: 15163682]

Mitchell JP, Macrae CN, Banaji MR. Dissociable medial prefrontal contributions to judgments of similar and dissimilar others. Neuron 2006;50:655-663. [PubMed: 16701214]

Moran JM, Macrae CN, Heatherton TF, Wyland CL, Kelley WM. Neuroanatomical evidence for distinct cognitive and affective components of self. Journal of Cognitive Neuroscience 2006;18:1586-1594. [PubMed: 16989558]

Morcom AM, Good CD, Frackowiak RS, Rugg MD. Age effects on the neural correlates of successful memory encoding. Brain 2003;126:213-229. [PubMed: 12477708]

Mueller JH, Wonderlich S, Dugan K. Self-referent processing of age-specific material. Psychology and Aging 1986;1:293-299. [PubMed: 3267409]

Otten LJ, Rugg MD. When more means less: Neural activity related to unsuccessful memory encoding. Current Biology 2001;11:1528-1530. [PubMed: 11591321]

Park DC, Polk TA, Park R, Minear M, Savage A, Smith MR. Aging reduces neural specialization in ventral visual cortex. Proceedings of the National Academy of Sciences USA 2004;101:1309113095.

Persson J, Sylvester C-YC, Nelson JK, Welsh KM, Jonides J, Reuter-Lorenz PA. Selection requirements during verb generation: Differential recruitment in older and younger adults. NeuroImage 2004;23:1382-1390. [PubMed: 15589102]

Persson J, Lustig C, Nelson JK, Reuter-Lorenz PA. Age differences in deactivation: A link to cognitive control? Journal of Cognitive Neuroscience 2007;19:1021-1032. [PubMed: 17536972]

Reuter-Lorenz PA, Jonides J, Smith EE, Hartley A, Miller A, Marshuetz C, Koeppe RA. Age differences in the frontal lateralization of verbal and spatial working memory revealed by PET. Journal of Cognitive Neuroscience 2000;12:174-187. [PubMed: 10769314]

Reuter-Lorenz PA, Lustig C. Brain aging: Reorganizing discoveries about the aging mind. Current Opinion in Neurobiology 2005;15:245-251. [PubMed: 15831410]

Salthouse TA. The processing-speed theory of adult age differences in cognition. Psychological Review 1996;103:403-428. [PubMed: 8759042]

Shipley, WC. Shipley Institute of Living Scale. Western Psychological services; Los Angeles: 1986.

Smith S, Jenkinson M, Beckmann C, Miller K, Wollrich M. Meaningful design and contrast estimability in FMRI. NeuroImage 2007;34:127-136. [PubMed: 17070706] 
Touryan SR, Johnson MK, Mitchell KJ, Farb N, Cunningham WA, Raye CL. The influence of selfregulatory focus on encoding of, and memory for, emotional words. Social Neuroscience 2007;2:1427. [PubMed: 18633804]

Wagner AD, Davachi L. Cognitive neuroscience: Forgetting of things past. Current Biology 2001;11:R964-R967. [PubMed: 11728323]

Wagner AD, Schacter DL, Rotte M, Koutstaal W, Maril A, Dale AM, Rosen BR, Buckner RL. Building memories: Remembering and forgetting of verbal experiences as predicted by brain activity. Science 1998;281:1188-1191. [PubMed: 9712582]

Wagner AD, Shannon BJ, Kahn I, Buckner RL. Parietal lobe contributions to episodic memory retrieval. Trends in Cognitive Science 2005;9:445-453. 


\section{Adjective Recognition}

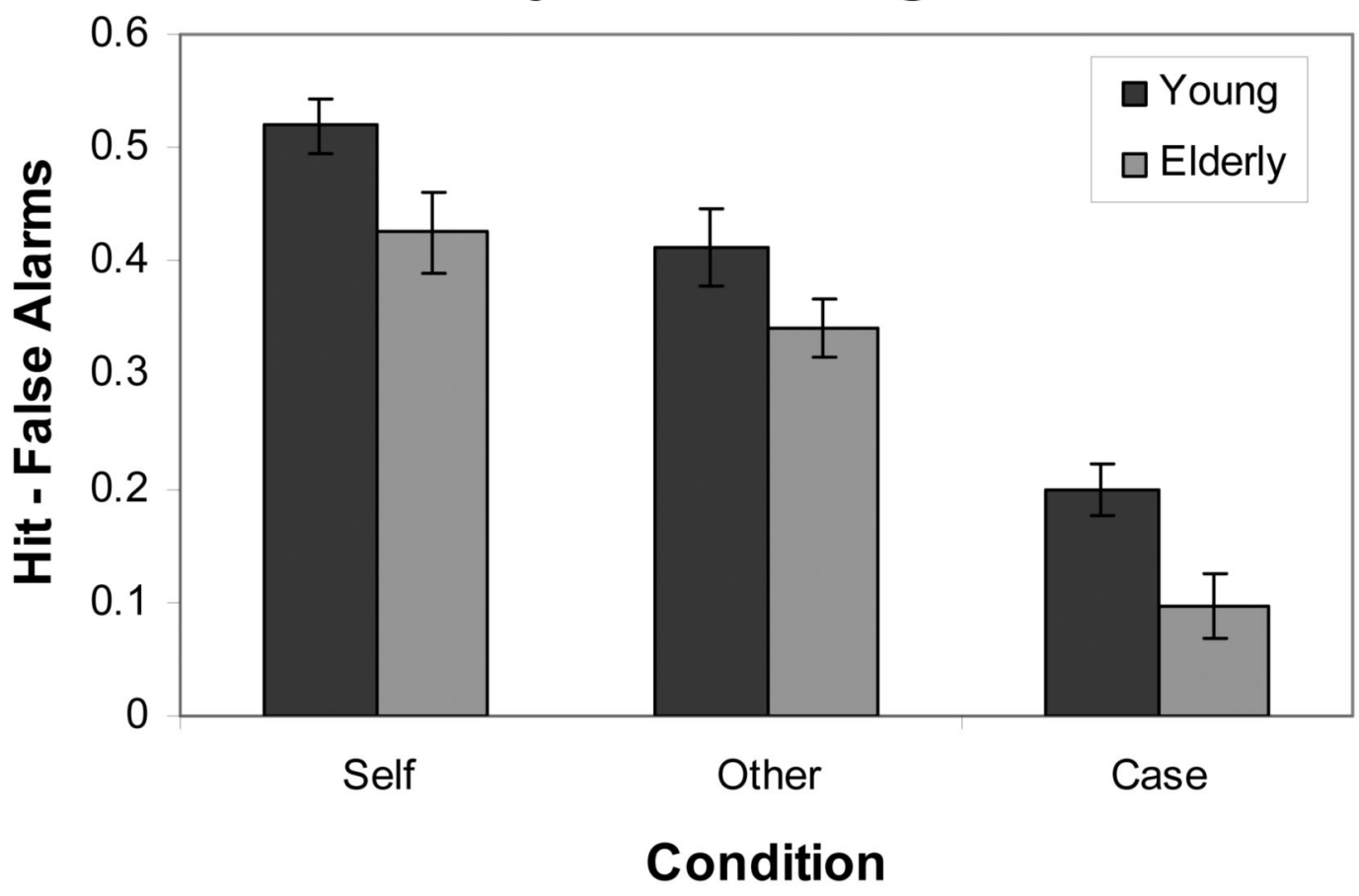

Figure 1.

Recognition performance. 

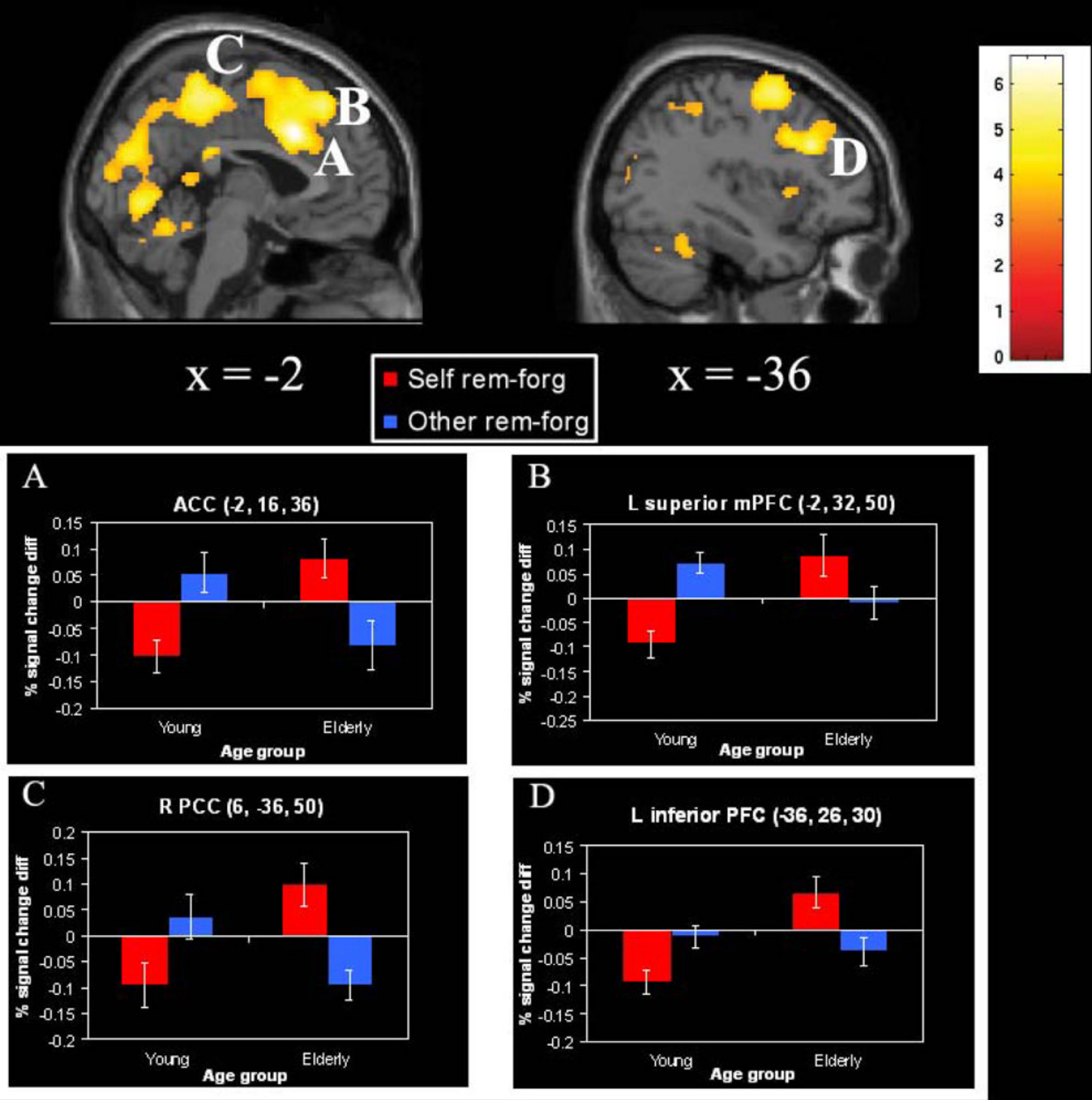

Figure 2.

Age differences in subsequent memory for self- vs. other-referenced trials. 
Table 1

Demographic and neuropsychological data for each age group.

\begin{tabular}{|l|l|l|l|}
\hline & Young & Elderly & p-value \\
\hline $\begin{array}{l}\text { Years of } \\
\text { Education }\end{array}$ & $\begin{array}{l}15.94 \\
(1.57)\end{array}$ & $\begin{array}{l}15.60 \\
(2.32)\end{array}$ & .63 \\
\hline $\begin{array}{l}\text { Self-rated } \\
\text { health }\end{array}$ & $3.63(.62)$ & $4.07(.70)$ & .07 \\
\hline $\begin{array}{l}\text { Digit } \\
\text { Comparison }\end{array}$ & $\begin{array}{l}81.18 \\
(12.05)\end{array}$ & $\begin{array}{l}53.93 \\
(8.13)\end{array}$ & $<.001^{*}$ \\
\hline Vocabulary & 35.29 & 37.13 & .06 \\
$(2.62)$ & $2.61)$ & \\
\hline MMSE & N/A & $29.73(.59)$ & \\
\hline & & & \\
\hline
\end{tabular}

Self-rated health reflects a rating on a 5-point scale in comparison to others in one's age group. A rating of 3 denotes "average" and 4 denotes "better than average".

* Significant at $\mathrm{p}<.001$ 


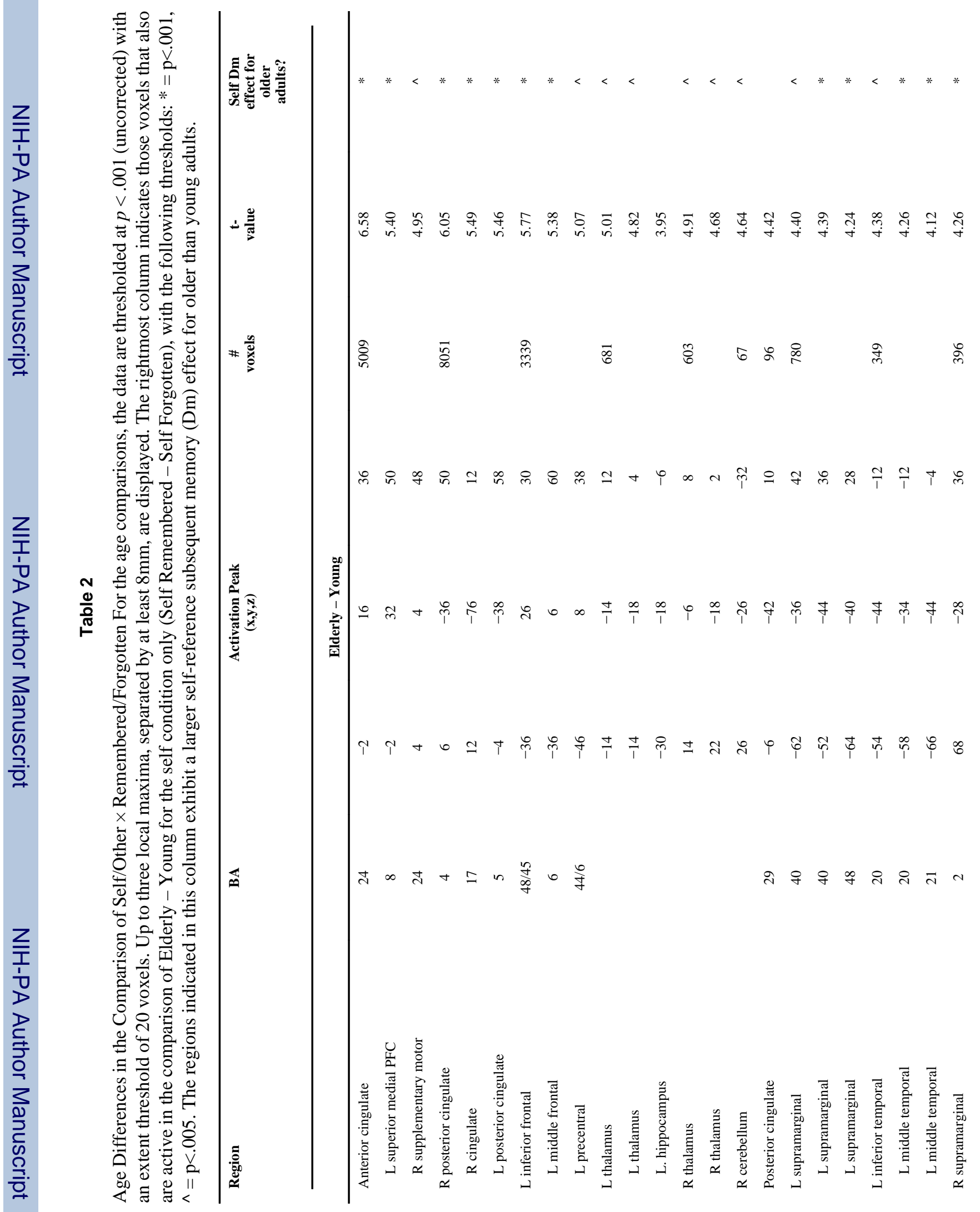




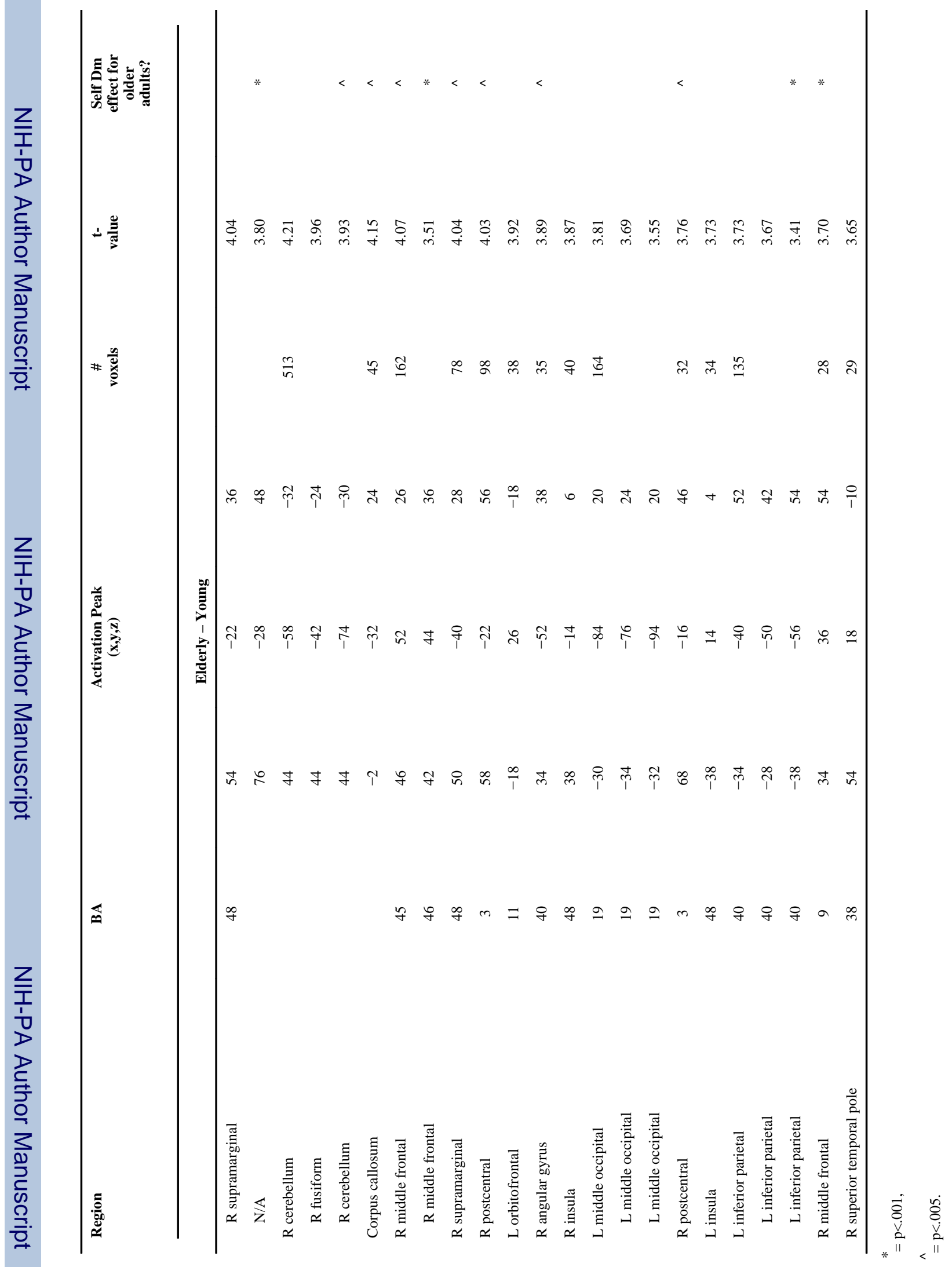

Neuropsychologia. Author manuscript; available in PMC 2011 January 1. 


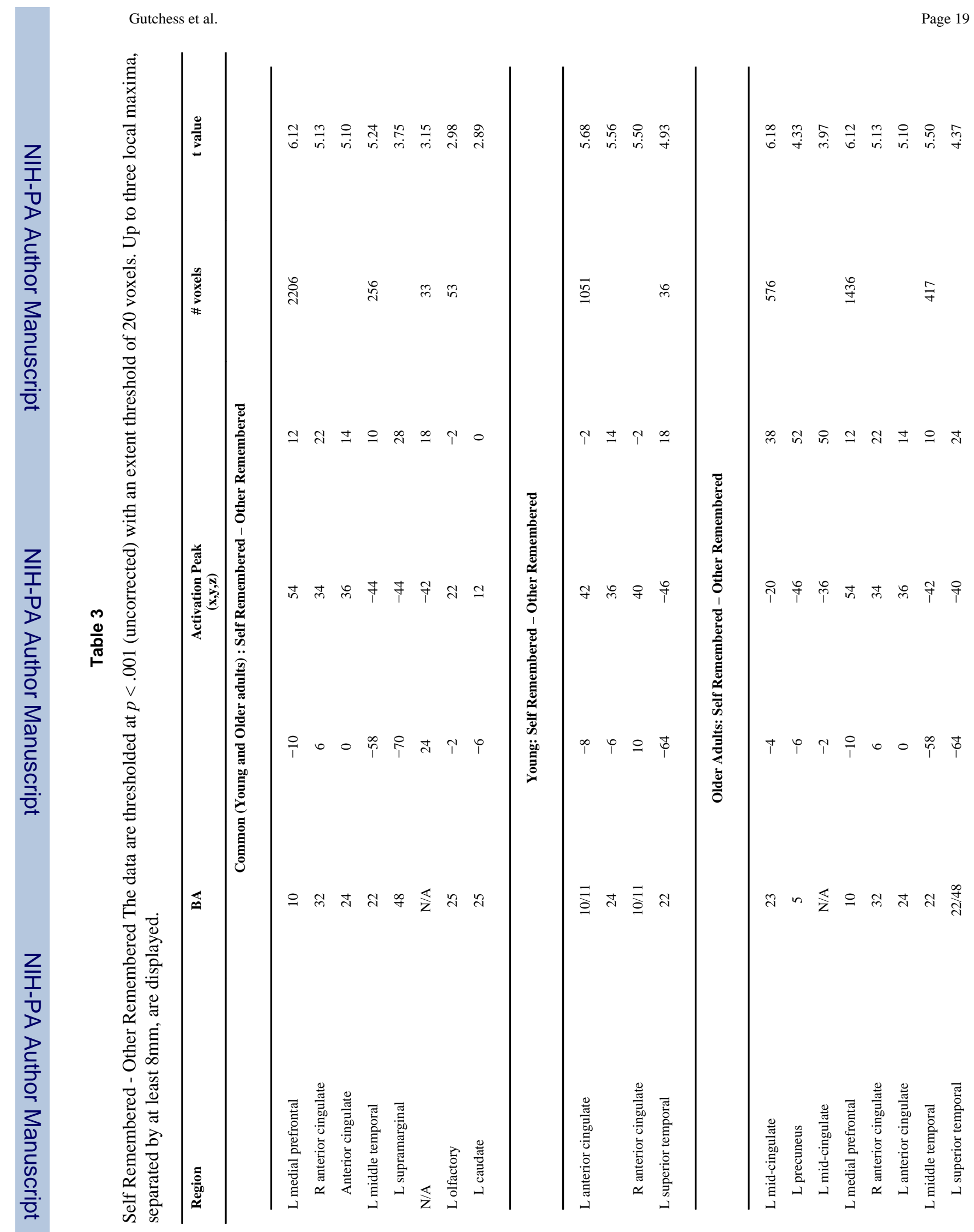

Neuropsychologia. Author manuscript; available in PMC 2011 January 1. 


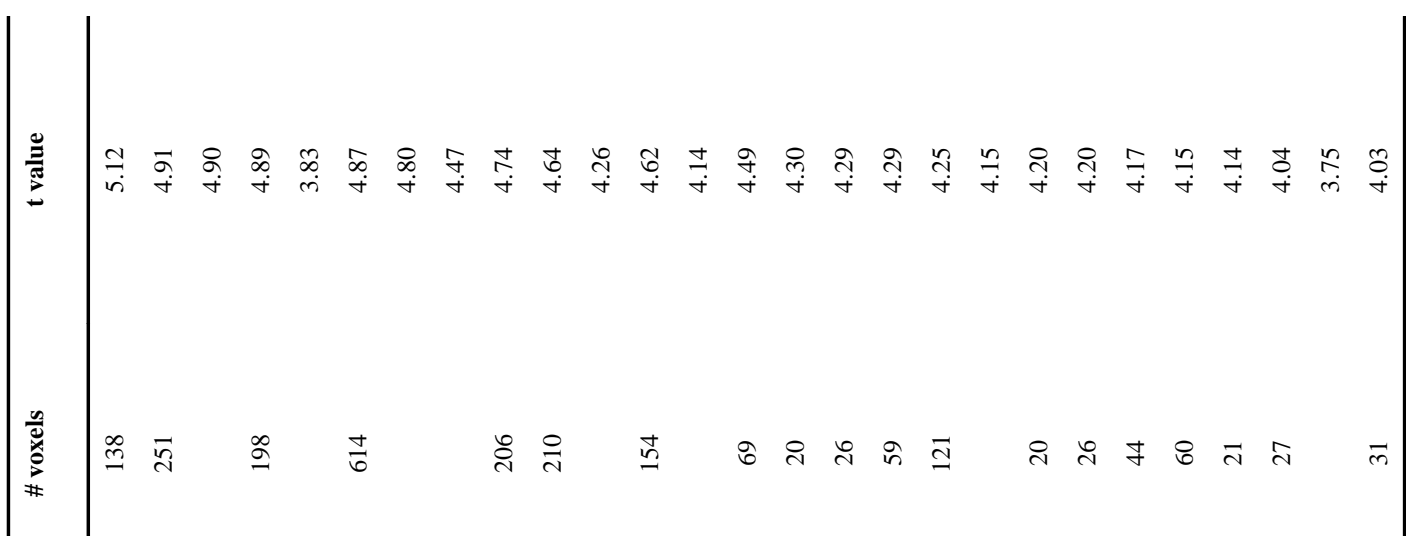

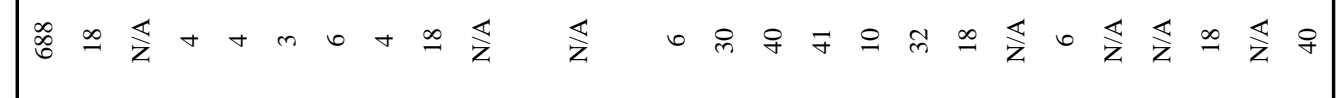

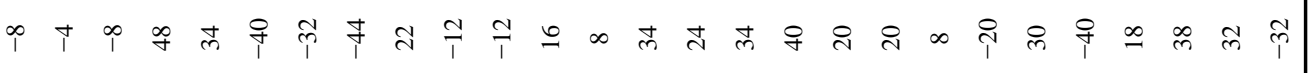

